\title{
TECENDO REDES LINGUÍSTICAS - POR QUE A COMPARAÇÃO ENTRE IDIOMAS AUXILIA NO APRENDIZADO ${ }^{1}$
}

Weaving Linguistic Webs - Why Language Comparison Helps In Learning

Sabine DENGSCHERZ, Universidade de Viena Tradução de Gisele Jordana EBERSPÄCHER - UFPR

\begin{abstract}
RESUMO: No artigo, Sabine Dengscherz busca levantar a discussão da função da tradução e comparação entre língua materna ou outras línguas dominadas pelo o aluno e o idioma que está adquirindo em sala de aula. Partindo da leitura de bibliografia na área e de exemplos, a autora defende que a comparação é uma importante ferramenta para incentivar a criação de redes linguísticas, o que, por sua vez, auxilia no aprendizado de novos idiomas.
\end{abstract}

PALAVRAS-CHAVE: aquisição linguística; redes linguísticas; comparação entre línguas; tradução no ensino de língua estrangeira

ABSTRACT: In the article, Sabine Dengsherz raises the discussion on the function of the translation and comparison between the mother language or other languages mastered by the student and the language being acquired in the classroom. Considering both the literature of the area and practical examples, the author defends that the comparison is an important tool to the creation of linguistic nets, which, on its turn, helps by the learning of new languages.

KEYWORDS: linguistic acquisition; linguistic nets; language comparison; translation into foreign language teaching

André Kostolany, um sábio especulador financeiro, gostava de falar sobre a dificuldade de conseguir o "primeiro milhão" - depois disso, o resto não seria tão difícil. O guru da bolsa de valores começou sua carreira na crise econômica de 1929 e ficou conhecido por sua flexibilidade e por contar piadas em húngaro, alemão, inglês e francês. Ele poderia muito bem ter cunhado uma expressão sobre seu poliglotismo: ter uma base sólida, a partir da qual pode-se continuar construindo, não é importante apenas para conseguir dinheiro, mas também para aprender idiomas.

Nosso capital de base consiste pelo menos na(s) nossa(s) língua(s) materna(s),

\footnotetext{
${ }^{1}$ Artigo publicado originalmente em língua alemã na Revista ÖDaF-Mitteilungen. Österreichischer Verband für Deutsch als Fremdsprache/Zweitsprache. v. 24, no. 2, novembro de 2008. Disponível em: < $<$ https://www.oedaf.at/site/wirueberuns $>>$
} 
que na nova literatura é/são chamada(s) com mais frequência com o termo mais neutro primeira língua. Quando uma criança aprende pelo menos uma língua em um nível avançado, ela desenvolve a capacidade de aprender outros idiomas (BUTZKAMM, 2002, p. 22). Se uma criança perde a chance (por exemplo, por falta ou ausência de input) de aprender profundamente pelo menos uma língua desde o início, ela ficará também sem uma base linguística sob seus pés. A criança corre o risco de um semilinguismo, marcado por uma dificuldade de expressão não só na primeira língua, mas também nas línguas estrangeiras que serão aprendidas posteriormente ${ }^{2}$. Essa situação traz inúmeras consequências, já que a consciência linguística é uma chave não só para o acesso a um primeiro conteúdo linguístico, mas também uma ferramenta linguística compartilhada (SCHMÖLZER-EIBINGER, 2008, p. 45).

O input linguístico que recebemos quando crianças marca nossa vida. Se você está lendo este texto, provavelmente pertence aos privilegiados. E eu, que lhe escrevo, obviamente também. Nós recebemos nosso capital linguístico em casa e o ampliamos ao longo das nossas vidas ou, por assim dizer, fizemos algo com ele. Nós somos os intelectuais. Nós lemos e aprendemos muito, temos um repertório de estratégias ao qual recorremos quando nos deparamos com novos conteúdos e aprendemos por toda a nossa vida - o que inclui ou incluirá, provavelmente, aprender novos idiomas.

\section{ALUNOS COMPARAM LÍNGUAS}

Quando somos confrontados com o novo e o desconhecido - o que acontece inevitavelmente no aprendizado de línguas estrangeiras - buscamos em nossa memória relações possíveis com o que já sabemos. Isso alivia o processo de aquisição do novo conteúdo. Esses pontos de contato podem acontecer antes mesmo de qualquer conhecimento linguístico prévio.

Doris Wildenauer-Józsa, em seu estudo Sprachvergleich als Lernenrstrategie (Comparação Linguística como Estratégia, 2005), pesquisou em que medida os alunos de fato usam a transferência de conhecimento. Ela identificou um desequilíbrio entre a perspectiva do aluno e a oferta em sala de aula: a comparação entre idiomas se encontra

\footnotetext{
${ }^{2}$ Essa relação foi descrita por Katharina Brizić no estudo Das geheime Leben der Sprachen. Gesprochene und verschwiegene Sprachen und ihr Einfluss auf den Spracherwerb in der Migration (2007).
} 
"principalmente na cabeça do aluno, enquanto não há lugar na sala de aula para se ocupar com hipóteses dos alunos ou com a troca de conhecimentos linguísticos e experiências individuais" (WILDENAUER-JÓZSA, 2005, p. 113).

Mas alunos gostam de expressar em um plano metalinguístico suas observações e com frequência falam sobre traduções para suas línguas (como apresentado em OOMEN-WELKE/KRUMM, 2004, p.9).

Para sua pesquisa, Doris Wildenauer-Józsa entrevistou 40 alunos ou alunas adultos, que frequentam um curso de nível intermediário em Freiburgo, em entrevistas semiabertas sobre seus comportamentos para aprender. A maioria deles dispõe de uma consciência contrastiva (mais sobre isso pode ser visto em LUTJEHARMS, 1999, p.11).

Quase $90 \%$ dos entrevistados concordam que a comparação e tradução entre idiomas ajuda no processo de aprendizado. Com isso, não querem apenas usar um processo de aprendizagem mais econômico ou eficiente, mas também ampliar seus conhecimentos sobre línguas, compreender diferenciações nos significados das palavras ou entender melhor os textos. A primeira língua tem um papel central nesse processo, mas outros idiomas estrangeiros também podem ser usados nas comparações (WILDENAUER-JÓZSA, 2005, p. 143-150).

Segundo Silke Demme (2001), alunos tchecos de alemão também afirmam que a comparação com a língua materna é significativa para o processo de aprendizagem: $24 \%$ afirmam que a comparação os ajuda com frequência, enquanto $52 \%$ afirmam que os ajuda às vezes.

Vocabulário e gramática são consideradas as áreas em que a comparação entre idiomas é tida como mais útil, sendo, portanto, as áreas centrais para a pesquisa de Wildenauer-Józsa.

Cerca de $87 \%$ dos entrevistados veem semelhanças entre palavras alemãs e palavras de suas línguas maternas. Além disso, estrangeirismos, semelhanças entre inglês e alemão e palavras estrangeiras vindas do latim também são comparações frequentes. Curiosamente, a percepção de falsos cognatos é um tema menos recorrente: menos da metade dos entrevistados via isso como um problema e apenas uma pessoa conseguiu lembrar mais de dois exemplos de palavras desse tipo (WILDENAUERJÓZSA, 2005, p. 135). Problemas de tradução de palavras entre a língua materna e o alemão são familiares para os entrevistados, e mais da metade conseguiu dar exemplos 
de casos como esses (WILDENAUER-JÓZSA, p.137-142).

A comparação entre as línguas acontece também na aprendizagem de gramática. Quase três quartos dos entrevistados reconheciam semelhanças entre gramáticas de línguas diferentes e quase dois terços conseguiu nomear essas semelhanças. O fato de que $\mathrm{o}$ foco seja evidentemente maior nas semelhanças e não nas diferenças provavelmente "se reduz ao fato de que alunos de gramática trazem consigo a percepção que as semelhanças entre as línguas têm o efeito de facilitar o aprendizado" (WILDENAUER-JÓZSA, p. 55). Por isso não se usa apenas comparações entre línguas semelhantes ou próximas, mas também entre alemão e japonês ou suaíli. Normalmente, as características comuns são vistas apenas pelo observador ou observadora, mas com frequência isso se dá por motivos estruturais ou tipológicos ou ainda podem ser reduzidos a contatos entre os idiomas. Por exemplo, algumas semelhanças em nível fraseológico podem ser identificadas entre o alemão e o húngaro (DENGSCHERZ, 2008).

A comparação entre idiomas também surte efeitos positivos na competência intercultural e na consciência linguística da primeira língua. 93,8\% dos entrevistados da pesquisa de Wildenauer-Józsa afirmaram refletir sobre a própria língua materna quando aprendem línguas estrangeiras (2005, p. 55 e p. 216).

\section{APRENDIZAGEM EM REDE ADAPTADA PARA A MEMÓRIA}

"O próprio é a chave para o estranho", disse Hans Drumbl em um ensaio curto intitulado Sprachunterricht und Ausbildung zur Mehrsprachigkeit (Ensino de idiomas e formação para o multilinguismo, 2008). "Metáforas se dirigem a nós e prometem prestar serviços como veículo do pensamento quando sua imagem corresponde a uma outra imagem que já fizemos sobre os fatos do mundo. Uma imagem encontra uma outra imagem e elas crescem uma pela outra, juntas" (p. 299), afirma. Drumbl faz aqui uma reflexão sobre uma metáfora de André Gide, de que as pessoas deveriam abandonar seus conhecimentos sobre o próprio e conhecido para abrir espaço para o novo e o desconhecido.

É como se estivéssemos na beira de uma piscina. Nós pulamos e, com o impulso, conseguimos alcançar um ritmo agradável com facilidade. Se a beira da piscina não fosse construída em uma base tão segura da qual pudéssemos pular, e para a qual 
podemos voltar quando necessário, precisaríamos de mais esforço para alcançar esse ritmo. Se, por um lado, quando nos agarramos a uma beirada segura não conseguimos ir muito longe, por outro lado, quando ignoramos completamente nossa beirada segura, sem sequer tocar nela, fazemos com que tudo seja mais difícil do que necessário. Sim, precisamos nos jogar por completo para ganhar impulso, mas também devemos lembrar de onde estamos saindo. E devemos sempre voltar para o conhecido, para nos segurarmos um pouco e não nos afogarmos completamente no novo.

Se, como alunos de idiomas, somos alimentados com informação em excesso, nos sentimos exaustos. Mas diminuir o input ao mínimo de novidade possível nos deixará entediados e fará com que percamos todo o interesse em aprender. A dificuldade dos professores e outras pessoas envolvidas no ensino de idiomas - assim como para mim, na hora de escrever este texto - é essencialmente a seguinte: por um lado, devemos identificar o que pode ser dado como pressuposto e o que pode ser novo para os alunos ou receptores e, por outro lado, encontrar conteúdos que sejam considerados interessantes e importantes por nosso público alvo (ROTH, 1997, p. 229).

Salvar uma informação em nossa mente ou absorver de fato um input linguístico são ações que dependem de vários fatores (BOECKMANN, 2008, p. 8). Além da significação e da novidade, às quais atribuímos os respectivos estados das coisas, a atenção, as emoções e as motivações também têm um papel importante.

O nível de atenção pode ser aumentado usando apresentações com diversos estímulos, e as emoções podem ser provocadas tanto pelo conteúdo ensinado quanto pelo ambiente e as condições de ensino. Um ambiente descontraído incentiva o processo de aprendizagem, enquanto o medo trava ou até paralisa esse processo. A motivação se distingue em dois tipos: a extrínseca e a intrínseca. A extrínseca depende de fatores externos, como o desejo de ter boas notas, reconhecimento, recompensas e assim por diante, enquanto fatores intrínsecos são, em outras palavras, a "alegria em aprender" e são um impulso muito eficaz. Quando a aprendizagem causa alegria, o interesse aumenta e as experiências pessoais ajudam a fixar o conteúdo. E quando o aluno faz conexões positivas, continua aprendendo com alegria, o que gera ainda mais experiências bem sucedidas e assim por diante.

A comparação entre idiomas pode ser uma parte pequena de um mecanismo de ensino de idioma bem ajustado, porque nosso cérebro guarda conteúdos na forma de 
redes: "a informação fica salva no cérebro na forma de conexões entre neurônios" (SPITZER, 2007, p. 72). Essas relações surgem com frequência de associações e podem ser organizadas de forma hierárquica. Elas podem ser fortalecidas por meio de prática (ROTH, 1997, p. 232) e, assim, o processo de ativação se automatiza gradualmente e o conhecimento declarado se torna uma capacidade procedimental: quando um dos nós da rede recebe um impulso, os nós que estão relacionados a ele também são ativados (NEUNER-ANFINDSEN, 2005, p. 54). A nossa mente então está na situação de produzir declarações linguísticas diretamente, sem que seja necessário recorrer a uma norma.

Essa imagem do cérebro como uma rede esclarece, entre outras coisas, por que o aprendizado com listas de vocabulário é tão pouco eficiente. Como essas listas mostram apenas palavras, sem nenhum contexto no qual podem aparecer, como em textos autênticos ou até mesmo frases simples, se perde a possibilidade de relação. Uma vez que nosso cérebro é construído por relações e é composto por proximidade no aprendizado, quando encontramos palavras e outros conteúdos com os quais ainda não temos relações de sentido, tentamos construí-las: "essa palavra fica aqui em cima à esquerda" ou "isso fica próximo da palavra X". Se uma palavra é organizada tematicamente, as chances de uma ligação acontecer aumentam, mas, se ela for apresentada em um texto, outras possibilidades de relação são oferecidas pelo próprio conteúdo - e se o texto estabelecer alguma relação emocional com o aluno e despertar seu interesse, outros fatores entram em jogo, fortalecendo ainda mais o processo de aprendizado.

Quanto maiores forem as possibilidades de conexão e mais nos for oferecido em termos de rede, o conteúdo será organizado e retomado mais facilmente (BOECKMANN, p. 9). Tudo isso corrobora o uso de textos autênticos em sala de aula, já que as palavras estão em um texto com conexões tecidas e traçadas.

Nesse contexto, o uso de tradução e comparação entre línguas é uma grande ferramenta, já que oferece possibilidades de criação de relações com um conhecimento que já é dominado pelo aluno. Os momentos de descoberta, em que o aluno se dá conta de semelhanças e diferenças, incentivam o interesse e os sentimentos positivos e aumentam a motivação intrínseca. 


\section{COMPARAÇÃO ENTRE LÍNGUAS NA SALA DE AULA}

São vários os motivos pelos quais as comparações linguísticas e a tradução recebiam pouca atenção nas salas de aula até agora. Existem pelos menos duas dificuldades mais latentes: em primeiro lugar, professores lidam com frequência com turmas não homogêneas, com falantes de várias línguas, fazendo com que fique difícil encontrar uma base igual para a comparação. Em segundo lugar, não se pode exigir que os professores dominem todas as línguas faladas por seus alunos.

De fato, isso não pode ser exigido. Os professores não ganham nada a mais para aprender outras línguas: eventualmente podem até se divertir com isso, mas normalmente não têm mais tanto tempo para se dedicar a outros idiomas. E, considerando turmas não-homogêneas, não faz muito sentido fazer comparações apenas entre duas línguas.

Mas nada disso é necessário. Se quisermos dar mais espaço para a comparação entre línguas na nossa sala de aula, podemos começar a encorajar os alunos a pensar mais sobre seus próprios idiomas e dar espaço para suas considerações e observações em sala. Podemos também começar a ver os alunos como especialistas em suas línguas, como fontes para outras línguas que não a que estamos ensinando. Podemos começar a dar espaço para todas as línguas faladas no grupo, para que os alunos se sintam encorajados a trocar informações sobre suas primeiras línguas entre si e comparar estruturas e formas de pensar. A língua franca nesse processo é o idioma da aula, no nosso caso o alemão. Quando os alunos falam em alemão sobre suas línguas maternas, fortalecem a consciência linguística das duas línguas. Além disso, eles também vão precisar de subsídios para se expressar metalinguisticamente sobre suas línguas em uma língua estrangeira - o que não é pouco.

Podemos apoiar nossos alunos, entre outras coisas, demonstrando interesse por suas línguas maternas, fazendo perguntas, lendo um pouco sobre diferentes estruturas linguísticas, tipologia linguística e materiais sobre comparação linguística e tradução. Então será mais fácil ajudar os alunos a conectar a terminologia da língua alemã com as terminologias de suas próprias línguas - o que nós provavelmente não saberíamos fazer sozinhos.

Com isso podemos também incentivar a comparação entre línguas e a tradução 
de maneira mais orientada. Ingrid Gürtler recomenda desde 1981 que professores possam ensinar a língua materna e os alunos as línguas estrangeiras ao mesmo tempo (GÜRTLER, 1981, p. 14) - um esforço frutífero e empolgante, que em tempos de canetas vermelhas e planos orçamentários é raramente viável (principalmente porque professores idealistas terão mais trabalho não remunerado para fazer).

Mas não são necessários grandes projetos - a comparação entre línguas também é viável de maneiras mais simples. Contos populares, expressões idiomáticas e palavraschave podem ser o ponto de partida para a comparação e a tradução, assim como alguns tipos textuais que existem em vários idiomas - como instruções de uso ou anúncios.

Quando várias línguas devem ser levadas em consideração, pode-se usar exercícios de tradução (para que se encontre, por exemplo, semelhanças e diferenças entre estruturas gramaticais) ou um "telefone sem fio" ${ }^{3}$ com várias línguas (priorizando a diversão e os conhecimentos metalinguísticos). Além disso, os próprios alunos podem procurar em textos estruturas que sejam próximas às suas línguas maternas. Isso incentiva que os alunos sejam mais independentes. Para isso são indicados exercícios mais abertos, para que os alunos tenham espaço para apresentar suas próprias descobertas.

O conceito de autonomia do aluno é um avanço inquestionável para a aula ideal. A comparação entre línguas e a tradução são oportunidades de permitir e de incentivar essa autonomia. $\mathrm{O}$ fato de que podemos, com isso, aprender um pouco mais sobre outras línguas é um efeito colateral bem-vindo. E estamos novamente no lucro - para todos os participantes. Quem investe tem capital para multiplicar. Isso vale tanto para o dinheiro quanto para nosso capital linguístico, que felizmente é menos suscetível a crises e tem bons juros de rendimento. Uma conjuntura favorável é composta, nesse caso, de uma atmosfera agradável para a aprendizagem, com inputs abundantes e inúmeras possibilidades de conexão do novo conhecimento com o conhecido, seja ele

\footnotetext{
${ }^{3}$ Um dos alunos pensa em uma frase e a sussurra no ouvido de outro colega. O próximo fala a frase em outra língua, que o terceiro colega deve traduzir novamente para o idioma comum ou ainda para uma terceira língua e assim por diante. A frase faz, com poucas ou várias alterações, a volta completa. Para que todos sejam incluídos, é importante certificar-se de que uma língua, que não a ensinada em sala, seja falada por pelo menos dois colegas da sala. Uma variante é fazer a atividade em forma escrita, passandose uma folha em que só se possa ver a última frase escrita. Essa versão da atividade faz com que as mudanças possam ser percebidas com maior facilidade. Mas a versão escrita não tem só vantagens: com ela será possível identificar os erros de tradução, o que pode constranger alguns alunos.
} 
conhecimento de mundo ou conhecimento linguístico. E então podemos, juntos, tecer redes linguísticas e as línguas que falamos (ou aprendemos a falar) crescem umas com as outras.

\section{REFERÊNCIAS}

BOECKMANN, Klaus-Börge. Der Mensch als Sprachwesen - das Gehirn als Sprachorgan. Fremdsprache Deutsch 38. 5-11. 2008.

BRIZIĆ, Katharina. Das geheime Leben der Sprachen. Gesprochene und verschwiegene Sprachen und ihr Einfluss auf den Spracherwerb in der Migration. Münster: Waxmann Verlag, 2007.

BUTZKAMM, Wolfgang. Psycholinguistik des Fremdsprachenunterrichts. Tubinga e Basileia: A. Francke UTB, 2002.

DEMME, Silke. Transfer und Interferenz: Lernprobleme für DaF-Studierende (nicht nur) mit tschechischer Muttersprache. In: WOLFF, Armin e WINTERS-Ohle, Elmar. Wie schwer ist die deutsche Sprache wirklich? Ratisbona: Becker-Kuns Verlag, 2011, p. 570-582.

DRUMBL, Hans. Sprachunterricht uns Ausbildung zur Mehrsprachigkeit. Bilder, Gedanken, Erinnerungen. In: SCHMÖLZER-EIBINGER, Sabine e WEIDACHER, Georg. Textkompetenz. Eine Schlüsselkompetenz und ihre Vermittlung. Festschrift für Paul R. Portmann-Tselikas zum 60. Geburtstag. Tubinga: Gunter Narr Verlag, 2007, p. 299-312.

GÜRTLER, Ingrid. Kontrastive Grammatik, kommunikativ. Arbeitsmöglichkeiten im Deutschunterricht. Tubinga: Gunter Narr Verlag, 1981.

LUTJEHARMS, Madeline. Tertiärsprache und Sprachbewusstheit. Was Lernende über den Einfluss der ersten Fremdsprache denken. Fremdsprache Deutsch 1. P. 7-11, 1999.

NEUNER-ANFINDSEN, Stefanie. Fremdsprachenlernen und Lernerautonomie. Sprachlernbewusstsein, Lernprozessorganisation und Lernstrategien zum Wortschatzlernen in Deutsch als Fremdsprache. Baltmannsweiler: Schneider Verlag Hohengehren, 2005.

OOMEN-WELKE, Ingelore; KRUMM, Hans-Jürgen. Sprachenvielfalt - eine Chance für den Deutschunterricht. Fremdsprache Deutsch 31. P. 5-13. 2004.

ROTH, Gerhardt. Das Gehirn und seine Wirklichkeit. Kognitive Neurobiologie und ihre philosophischen Konsequenzen. Frankfurt am Main: Suhrkamp, 1997.

SCHMÖLZER-EIBINGER, Sabine. Lernen in der Zweitsprache. Grundlagen und Verfahren der Förderung von Textkompetenz in mehrsprachigen Klassen. Tubinga: Gunter Narr Verlag, 2008. 
SCHMÖLZER-EIBINGER, Sabine e WEIDACHER, Georg (Org). Textkompetenz. Eine Schlüsselkompetenz und ihre Vermittlung. Festschrift für Paul R. PortmannTselikas zum 60. Geburtstag. Tubinga: Gunter Narr Verlag, 2007.

SPITZER, Manfred. Lernen. Gehirnforschung und die Schule des Lebens. BerlinHeidelberg: Spektrum Akademischer Verlag (Springer Verlag), 2007.

WILDENAUER-JÓZSA, Doris. Sprachvergleich als Lernstrategie. Eine Interviewstudie mit erwachsenen Deutschlernende. Freiburg im Breisgau: Fillibach Verlag, 2005.

WOLFF, Armin; WINTERS-OHLE, Elmar (org). Wie schwer ist die deutsche Sprache wirklich? Materialien Deutsch als Fremdsprache 58. Regensburg: Becker-Kuns Verlag, 2001. 